\title{
ALGUNOS RASGOS CARACTERÍSTICOS DE CALDERÓN EN LA COMEDIA LOS EMPEÑOS DE UN ACASO
}

\author{
Andreu Alfonso Barrios \\ Facultad de Filología \\ Universidad Nacional de Educación a Distancia (UNED) \\ Calle Juan del Rosal, 14, 28040 Madrid. España \\ andreu.alfonso@gencat.cat
}

[Anuario calderoniano (ISSN: 1888-8046), 7, 2014, pp. 13-32]

Juan de Vera Tassis publicó la Sexta parte de comedias de Calderón de la Barca en 1683, dos años después de la muerte del dramaturgo. El criterio de Vera para organizar esta parte y sus precedentes no se basaba en la búsqueda de un estricto orden cronológico de las comedias; tampoco organizó el compendio mediante una clasificación temática precisa, sino que buscó conscientemente una mezcolanza de géneros con el objetivo de atraer el interés del potencial comprador del volumen. La recopilación reúne un conjunto de obras con gran diversidad de argumentos y motivos temáticos. Vera Tassis incluye en esta compilación — se trata de la tercera obra de la Sexta parte- la comedia de capa y espada Los empeños de un acaso. Vera debía de tener muy clara la autoría de Calderón de esta obra; en el prólogo de 
la Verdadera quinta parte de comedias, publicada en 1682 - tan solo un año después de la muerte del poeta-Vera Tassis realiza unas Advertencias a los que leyeren y critica duramente la ligereza y codicia de algunos impresores cuando atribuyen a Calderón comedias no escritas por el dramaturgo"; Vera presenta un listado de "Comedias supuestas, que andan debajo de su nombre», precedido por un inventario de las "Comedias verdaderas de don Pedro", y en el apartado titulado "En los tomos de varias» incluye la obra Los empeños de un acaso como original de Calderón².

Para su publicación en la Sexta parte, Vera Tassis pudo utilizar como testimonio alguna de las dos ediciones sueltas - bajo el título Los empeños que se ofrecen - imputadas a Pérez de Montalbán ${ }^{3}$. Tras aquellas primeras publicaciones de la comedia, y ya atribuida a Calderón, aparece nuevamente la obra en el volumen de El mejor de los mejores libros que han salido de comedias nuevas, en dos ediciones datadas en 1651 y 1653.

En 1981, Maria Grazia Profeti defendió la autoría de Juan Pérez de Montalbán de Los empeños de un acaso ${ }^{4}$. Este dramaturgo, nacido en los albores del siglo XVII — hacia 1601 o 1602 - falleció prematuramente el 25 de junio de 1638, tras un período de dos años en los que sufrió un grave proceso de demencia. Su padre fue Alonso Pérez, un conocido librero que mantuvo una sugestiva relación con Lope de Vega a causa de su actividad profesional ${ }^{5}$. Precisamente el mismo año en que falleció el Fénix, 1635, se publicaron las primeras obras dramáticas de Pérez de Montalbán en el Primer tomo de las comedias y el autor redactó también un sentido texto de homenaje a su maestro, la

1 «La codicia de algunos libreros y la ignorancia de muchos trasladantes han ocasionado los innumerables errores que padecen todas las comedias de España, ya haciéndolas imprimir diminutas y defectuosas, o ya trasladándolas sin conocimiento dellas, intitulándolas unos y otros con supuestos autores, tanto por autorizar su maliciosa culpa cuanto por darlas más interesado valor, atrevimiento que no perdonó las siempre inimitables de aquel venerado fénix don Pedro Calderón de la Barca [...]». Ver Calderón, Verdadera quinta parte de comedias, p. 72.

${ }^{2}$ Eric Coenen (2009) analiza este inventario de Vera Tassis incluido en el prólogo de la Verdadera quinta parte.

3 Profeti, 1976.

${ }^{4}$ Profeti, 1983 (presentado en 1981 en el «Congreso Internacional sobre Calderón y el teatro español del Siglo de Oro", Madrid, 8-13 de junio).

${ }^{5}$ Ver Cayuela, 2005. 
Fama póstuma a la vida y muerta del doctor frey Lope Félix de Vega Carpio y elogios panegíricos a la inmortalidad de su nombre. Un mes después de la muerte de Pérez de Montalbán, su padre publicó el Segundo tomo de las comedias. La producción de este dramaturgo puede parecer pequeña si la comparamos con el reconocido desbordamiento de su mentor, pero resulta bastante considerable si nos atenemos a la juventud de Pérez Montalbán. Sus propias palabras en 1633 corroboran la entidad de su obra: «[...] ha escrito treinta y seis comedias y doce autos sacramentales. Ha impreso las Novelas ejemplares, el Orfeo en lengua Castellana, El Purgatorio de San Patricio, y este último libro que llama Para Todos, y tiene para sacar a la luz la prodigiosa vida de Malhagas el embustero, sin otros muchos libros, que por no gastar el tiempo consigo mismo no refiere» ${ }^{6}$.

En ninguna de las dos Partes de Comedias publicadas de Pérez de Montalbán aparece la comedia Los empeños de un acaso: no asoma en la Primera, publicada el año $1635^{7}$, ni tampoco en la Segunda, del año 16388; ambas partes (la segunda, impresa tras la temprana muerte del autor) fueron editadas por el padre del dramaturgo, el librero Juan Pérez. Hartzenbusch incluyó esta obra en su compilación de comedias de Calderón en la Biblioteca de Autores Españoles; en el catálogo cronológico del escritor que aparece en el volumen cuarto de esta misma colección ${ }^{9}$, Hartzenbusch propuso el año 1639 como fecha probable de redacción de Los empeños de un acaso, a tenor de cierta alusión en dicha comedia a un monstruo de dos cabezas ${ }^{10}$, que José

6 Pérez de Montalbán, Para todos, p. 10.

${ }^{7}$ Pérez de Montalbán, Primero tomo de las comedias del doctor Juan Pérez de Montalbán. Contiene doce comedias: $A$ lo hecho no hay remedio y Príncipe de los montes; El hijo del Serafín, San Pedro de Alcántara; Cumplir con su obligación; Los templarios; La doncella de labor; El Mariscal de Virón; La toquera vizcaína; Amor, privanza y castigo; Olimpia y Vireno; Lo que son juicios del cielo; El señor don Juan de Austria; Los amantes de Teruel.

8 Pérez de Montalbán, Segundo tomo de las comedias del doctor Juan Pérez de Montalbán. Contiene doce comedias: Como amante y como honrada; Segunda parte del Séneca de España; Don Florisel de Niquea; La deshonra honrosa; El valiente nazareno;Téagenes y Clariquea, Despreciar lo que se quiere; El divino portugués; Amor, lealtad y amistad; La ganancia por la mano; El valiente más dichoso; El sufrimiento premiado.

${ }^{9}$ Calderón, Comedias, p. 674.

10 « ¿No fuera el monstruo yo de dos cabezas? / ¡Oh cuanto lo estimara mi fortuna! / pues para discurrir tuviera una, / y otra para aparar; si con bien salgo / de esta, no más papeles» (III, vv. 389-393). 
Pellicer de Ossau había narrado en sus Avisos Históricos en una nota del 8 de noviembre de $1639^{11}$. A pesar de la imposibilidad de establecer tal indicio como única prueba concluyente de la datación de la comedia, el hecho narrado por Pellicer no parece tan común como para no tenerlo en cierta consideración ${ }^{12}$. Teniendo en cuenta la enfermedad mental que afectó a Pérez de Montalbán durante los últimos años de su vida ${ }^{13}$ y su temprana muerte en el año 1638, no parece posible atribuir a este dramaturgo la creación de Los empeños de un acaso si damos por válida la fecha de 1639 para la composición de la comedia.

Ahora bien, no resulta conveniente zanjar de forma tan ligera la atribución de esta comedia, sin tener en cuenta otras dimensiones del problema, dadas las similitudes de Pérez de Montalbán y de Calderón en algunos aspectos de la construcción dramática de sus obras. Como ya señaló Profeti ${ }^{14}$, la misma comedia apareció en diversas ediciones con dos títulos distintos - Los empeños de un acaso y Los empeños que se ofrecen - cuestión que probablemente pudo provocar los problemas de atribución conocidos. A mayor abundamiento, en el prólogo de la Cuarta parte de comedias, editada en Madrid en el año 1672, el mismo Calderón criticó la falta de miramientos y la codicia de ciertos impresores $^{15}$, que le imputaban la autoría de comedias que él no había

11 «En el condado de Aviñón en Francia, se dice por cierto que una labradora parió 'un monstruo con dos cabezas' que se besaban una a otra, y un solo cuerpo. Bautizáronle, y murió luego; abriéronse, y le hallaron solo un corazón» (Calderón, Comedias, IV, ed. Hartzenbusch, p. 674).

12 Profeti, consciente de que en la fecha propuesta por Hartzenbusch para la redacción de la comedia, Pérez de Montalbán ya estaba muerto, zanja de manera poco convincente tal posibilidad: «Pero fenómenos parecidos [monstruos de dos cabezas] aparecen citados desde la antigüedad clásica, y la referencia resulta demasiado tópica para que se le pueda conceder importancia. La comedia tiene que ser más temprana» $(1983$, p. 254).

13 «Agotadas las fuerzas intelectuales de este desdichado autor con tan continuo estudio y esfuerzo, fue asaltado de una enfermedad de cabeza, que llegó a rayar en frenesí, de cuyas resultas falleció en Madrid, a los treinta y seis años de edad, el 25 de junio de 1638, siendo enterrado en la parroquia de San Miguel (que hoy no existe)» (Mesonero Romanos, Dramáticos contemporáneos de Lope de Vega, pp. XXX-XXXI).

14 Profeti, 1983.

15 «[...] Yo con el deseo de obedecer en todo, a pesar del dejo con que ya miro esta materia y desimaginado (por el poco afecto que he puesto en andar en sus al- 
escrito; y acto seguido, presenta una lista de cuarenta y una comedias que afirma no ser obra suya, entre las que incluye Los empeños que se ofrecen. En defensa de Calderón, cabría decir que el dramaturgo debía considerar como ajena esta comedia, aún sin haber podido cotejar el texto ni comprobar que se trataba de la misma comedia Los empeños de un acaso que él había escrito, error que podría atribuirse por haberla considerado una comedia autónoma, a pesar del parecido del título.

Por otra parte, el título de la comedia - Los empeños de un acasose muestra bajo esta forma en diversas ocasiones a lo largo de la obra en el texto editado porVera ${ }^{16}$; la primera ocasión al final de la primera jornada, cuando doña Elvira se inquieta considerablemente, e indica a su criada que le prepare el manto (I, v. 1299), clausurando así el primer acto de la obra:

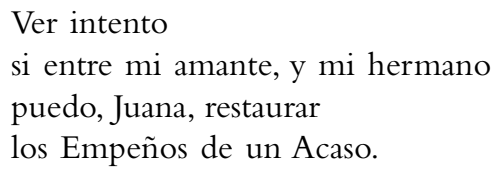

$\left(\mathrm{I}, \mathrm{vv}\right.$. 1300-1303) ${ }^{17}$

Esta expresión, que da título a la comedia tal y como la conocemos hoy, parece aludir a las veleidades del azar y la fortuna (por otra

cances) de lo que había de encontrar en ella, acudí a buscarlos y no solo hallé en sus impresiones que ya no eran mías las que lo fueron, pero muchas que no lo fueron, impresas como mías, no contentándose los hurtos de la prensa con añadir sus yerros a los míos, sino con achacarme los ajenos, pues sobre estar, como antes dije (las ya no mías) llenas de erratas y por el ahorro del papel aún no cabales (pues donde acaba el pliego acaba la jornada y donde acaba el cuaderno acaba la comedia), hallé, ya adocenadas y ya sueltas, todas estas que no son mías, impresas en mi nombre». Ver Calderón, Verdadera quinta parte de comedias, p. 5.

${ }^{16}$ Por el contrario, tal y como afirma Coenen, «[...] los versos finales de Los empeños que se ofrecen, tal como figuran en El mejor de los mejores libros de comedias, confirman incluso el título rechazado por Vera Tassis (acaban / los empeños que se ofrecen, / perdonad sus muchas faltas), y sólo en las jornadas primera y segunda se encuentran alusiones al título correcto, Los empeños de un acaso» (2009, p. 36).

${ }^{17}$ Los textos de las comedias citadas en este artículo pertenecen a la Segunda parte de comedias (El hombre pobre todo es trazas y El astrólogo fingido), la Tercera parte de comedias (El maestro de danzar, Mañanas de abril y mayo y También hay duelo en las damas) y la Sexta parte de comedias (Los empeños de un acaso). 
parte, un elemento consustancial al desarrollo dramático de este tipo de comedias de enredo), y es una fórmula parecida a la que unos versos antes fue expresada por don Diego ("por un acaso eso fue», I, v. 1287) y don Juan («que a hombres como yo obliga / los empeños de un acaso", I, vv. 1290-1291). Más tarde, en el segundo acto de la comedia, don Juan volverá a reiterar la misma expresión (II, v. 856), mientras espera a que llegue don Félix para batirse en duelo.

Se puede apreciar en Los empeños de un acaso una recurrencia de determinados motivos situacionales o dramáticos en muchas otras comedias de capa y espada escritas por Calderón. A pesar de que en toda la Comedia del Siglo de Oro existe un conjunto de características comunes y convenciones compartidas por la mayoría de dramaturgos, se puede observar que Calderón repite determinados tratamientos de temas y que éstos se presentan de forma parecida en diversas comedias de esta tipología. Con todas las prevenciones posibles que requiere un análisis de este tipo, y sin pretender realizar una demostración objetiva o interior ${ }^{18}$, podemos constatar numerosas coincidencias con otras obras del autor. Sin pretender ser exhaustivo en el análisis comparativo, comentaré tres cuestiones que aparecen en el desarrollo de la comedia Los empeños de un acaso y que tienen un tratamiento similar en las obras de capa y espada escritas por Calderón: la mención del locus amoenus, la consideración de la ciudad de Madrid como una urbe populosa, marco espacial de la mayoría de comedias de este género y los comentarios metaliterarios que el dramaturgo desliza con frecuencia en este tipo de obras.

El locus amoenus es uno de los tópicos más conocidos de la literatura clásica; ya es citado por Teócrito y Virgilio, y remite al espacio donde se desarrollaban las escenas pastoriles de la poesía bucólica. En la literatura medieval y renacentista abundan descripciones de parajes en los que destacan diversos elementos que se refieren a este lugar ameno como un retorno a la naturaleza. También en el Barroco es frecuente su uso; Calderón lo cita en varias comedias de capa y espada

${ }^{18}$ En su defensa de la atribución de Los empeños de un acaso a Pérez de Montalbán, Maria Grazia Profeti critica algunas metodologías analíticas que le parecen «muy sospechosas», aunque reconoce la existencia de un «idiolecto» propio de cada autor (1983, pp. 251-252). 
y desarrolla a veces una atribución simbólica de cualidades de la naturaleza a la belleza o el espíritu de la dama protagonista.

El tópico del locus amoenus aparece en la comedia Los empeños de un acaso. El extenso discurso de don Juan en la primera jornada de la obra (I, vv. 254-329) se desarrolla entre conceptos corteses e incide en la imagen de exaltación de la primavera como marco perfecto para la relación entre los amantes, que es expresada en términos bélicos y de conquista:

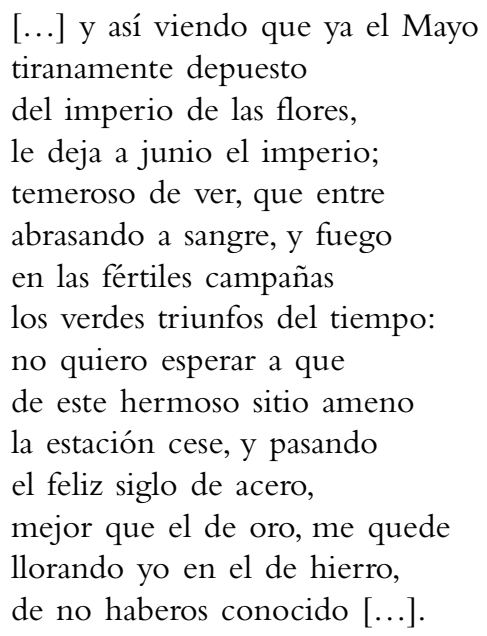

(I, vv. 284-298)

Don Diego se refiere levemente a su amor despechado con doña Leonor, pero la atención de la escena pasa rápidamente a don Juan, quien - para sorpresa e inquietud de doña Elvira- inicia el relato de su encuentro con la mujer tapada en el Parque; el caballero recurre nuevamente (como antes en I, vv. 284-298) a la idealización de la naturaleza domeñada por el hombre:

\author{
La ociosidad cortesana, \\ estas mañanas del mayo \\ me sacó a este verde sitio, \\ me llevó a este verde espacio, \\ que República de flores, \\ y laberinto de ramos, \\ de dosel sirviendo al río,
}


sirven de alfombra a Palacio.

Entre las confusas tropas, que errantemente bajando, coros de ninfas tejían mejor, que en Elísios campos; una tapada beldad al Parque bajó [...].

(I, vv. 1003-1016)

Hay muchos ejemplos del uso de este tópico en otras comedias de Calderón. En la primera jornada de El astrólogo fingido, don Juan conversa con doña María; tras varios ingeniosos juegos conceptuales, el caballero compara la belleza de la dama con la de la propia naturaleza, recordando el lugar donde se produjo el encuentro inicial entre ambos:

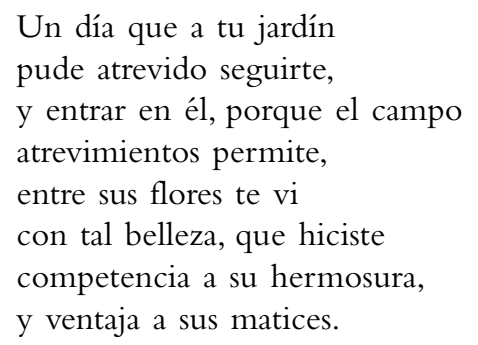

(I, vv. 164-171)

Este tipo de atribución también se advierte en la comedia Mañanas de abril y mayo. En este caso, el proceso de configuración simbólica presenta una fuerte oposición entre dos espacios: la caracterización conceptual de la casa de doña Ana como un lugar sagrado actúa como fuerte contraste con la descripción sensorial del Parque del Prado. La diferente connotación de los dos espacios (el parque del Prado y la casa de doña Ana) plantea una relación de conceptos contrarios que refleja las diversas concepciones del amor y el sentido de la vida de los diferentes personajes: mientras que doña Clara es la personificación de la vida sensual y el carpe diem, doña Ana representa la virtud; el Prado es «festín alegre» (I, v. 481) y la vivienda de la dama es «casa de deidad» (I, v. 702), elevando a doña Ana al rango de diosa. Sin duda, 
el espacio dramático fundamental de Mañanas de abril $y$ mayo es el Parque del Prado, que es descrito en la obra como un nuevo locus amoenus, una especie de lugar idílico cuya esencia es acentuada por la utilización del dramaturgo de una cancioncilla muy popular en la época ${ }^{19}$.

Ya mediado el primer acto de esta comedia, en un cuadro que representa el espacio dramático exterior del Parque del Prado, una escena muestra dos parejas de personajes en los dos lados opuestos del escenario (don Luis y don Hipólito por una parte y doña Clara e Inés por la opuesta) como bien anuncia don Hipólito: «pues estamos / en el campo dos a dos» (I, vv. 463-464). La criada Inés advierte la presencia de los dos caballeros y tranquiliza a su ama, asegurándole que no la reconocerán. Los dos caballeros se acercan a las mujeres para requebrarlas, y don Hipólito vuelve a apuntar el motivo del locus amoenus que representa el Parque, lugar de encuentro de relaciones amorosas, que es definido como un espacio de naturaleza domeñada y amable:

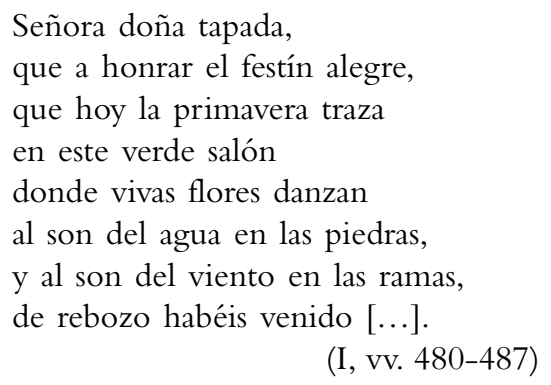

En una escena posterior, doña Clara e Inés, que venían huyendo desde el Parque de don Hipólito y don Luis (I, v. 541), solicitan refugio temporal en la casa de doña Ana, ante el acoso de los dos caballeros que las vienen siguiendo para conocer su identidad:



19 «Mañanitas floridas / de Abril, y Mayo, / despertad a mi niña / no duerma tanto» (I, vv. 388-391). 
mientras que un hombre pasa esa calle, sagrado vuestra casa sea de mi cuidado pues casa de deidad siempre es sagrado.

(I, vv. 695-702)

La diferente connotación de los dos lugares (el parque del Prado y la casa de doña Ana) presenta las diversas concepciones del amor entre los diferentes personajes, su sentido de la vida y la caracterización de los espacios dramáticos representados: mientras que doña Clara es la personificación de la vida sensual y el carpe diem, doña Ana representa la virtud; el Prado es "festín alegre» (I, v. 481) y la vivienda de la dama es "casa de deidad» (I, v. 702), elevando a doña Ana al rango de diosa. El sentido pagano y sensual de la naturaleza domeñada del Parque se contrapone a la espiritualidad y virtud que se respira en la casa de doña Ana; mientras que ésta se dirigía a Misa (I, v. 636), doña Clara se holgaba al amanecer con un paseo por el parque, con el objeto de vivir nuevas aventuras; la caracterización de los dos lugares enfrenta un espacio exterior sensual, el parque del Prado, lugar de encuentro público entre damas y caballeros, contra el espacio cerrado, de virtud y reconocimiento, que simboliza la casa de doña Ana.

Una de las características más reconocibles de las comedias de capa y espada es la marca de cercanía al espectador del teatro de corral del siglo XVII ${ }^{20}$ : esta pauta estilística se basa en la utilización de espacios dramáticos reconocibles por parte del público que asistía a la representación. Los personajes de estas obras viven en ciudades de la España contemporánea: Madrid, Sevilla, Valladolid, Valencia, Ocaña, etc. En la mayoría de las comedias de este género el espacio dramático representado es la ciudad de Madrid (La dama duende, El hombre pobre todo es trazas, El astrólogo fingido, Mañanas de abril y mayo, También hay duelo en las damas, Los empeños de un acaso, etc.).

Siendo Madrid la ciudad donde Calderón residió durante la mayor parte de su vida, y desarrolló la parte más importante de su actividad como dramaturgo (primero escribiendo comedias para los corrales y más tarde como poeta de la Corte) parece lógico que aparezcan

20 Arellano, 1988. 
con cierta frecuencia alusiones diversas a ciertas calles, plazuelas y lugares de la capital que reconocerían de inmediato los espectadores que asistían a las representaciones en los corrales del Príncipe y de la Cruz. Las comedias de capa y espada del dramaturgo están salpicadas de abundantes referencias espaciales a diversos barrios, calles o plazuelas del Madrid del XVII.

Un número elevado de espacios dramáticos —ocho- es representado en Los empeños de un acaso, cinco lugares exteriores y tres interiores; por orden de aparición en la comedia son los siguientes: una calle de Madrid, justo enfrente de la casa de doña Leonor; una calle indeterminada de Madrid; un Parque de la ciudad; los aposentos de doña Elvira; una calle de Madrid, justo enfrente de la casa de don Félix; un lugar cercano al monasterio de los Recoletos y los aposentos de don Juan. Se trata de una comedia que incluye diversas referencias a lugares de la ciudad que debían ser muy reconocibles para el espectador del corral de comedias contemporáneo a Calderón: se alude a las sillas del Refugio, Leganitos, el convento de agustinos recoletos descalzos, el camino de san Bernardino y el camino de las cruces.

La familiaridad del espectador del corral con los lugares citados en las comedias es un elemento que actúa como contrapunto a la trama compleja, enrevesada, y a veces inverosímil, con que se presentan los argumentos de este tipo de obras. Al espectador del corral del Príncipe o del corral de la Cruz (sitos en las calles del mismo nombre) le resultaría muy cercana la referencia a la calle mayor, la iglesia - el desmesurado crecimiento de la antigua villa había hecho proliferar por doquier estos edificios religiosos- o el Prado. En el plano trazado por Texeira en 1656 se aprecia que el crecimiento de la ciudad aún no había afectado al Prado Alto ni a las avenidas del Prado de San Jerónimo o del Prado de Atocha, que coincide básicamente con el paseo del mismo nombre de la ciudad actual. Se trataba de lugares de encuentro y paseo, a los que sin duda hacen referencia los personajes de la comedia.

Madrid es la ciudad que aparece con más frecuencia en las comedias de capa y espada de Calderón. Las referencias a Madrid, una ciudad importante y de gran densidad de población - y por tanto, llena de oportunidades y magnífica para quien necesita ocultarse- aparecen con cierta frecuencia. 
En Los empeños de un acaso, el criado Hernando comenta con don Juan el espacio representado en escena, la vivienda de un caballero al que buscan: «La casa dicen que es ésta / y él [don Félix] es, señor, el que está / aquí» (II, vv. 369-371). Don Juan refuerza la concreción del lugar con un nuevo dato de localización genérica: «[...] y hasta ahora ignoré la casa, / con ser de la mía tan cerca» (II, vv. 382-383). La inmediata reacción de don Félix parece insinuar la gran dimensión del Madrid del XVII, una gran ciudad en la que resulta dificil conocer a buena parte de sus habitantes, aún residiendo en el mismo barrio:

Esa es culpa de la Corte;
mas si yo, señor, supiera
que me buscábais, presumo,
que hubiera hallado la vuestra.

(II, vv. 384-387)

Esta descripción de Madrid como una ciudad grande y bulliciosa es tratada de parecida forma en diversas comedias de Calderón. Una de las características del subgénero de comedias de capa y espada es la construcción de un juego lúdico que demuestre la capacidad del dramaturgo para crear tramas enrevesadas e ingeniosas. Calderón es muy consciente de las dificultades que presenta la verosimilitud de la acción en este tipo de obras. Por ello, se esfuerza en mantener ciertas pautas de conexión con la realidad circundante, un rasgo común de estas obras. Se trata de marcas de proximidad al espectador, de diversa índole, que constituyen una de las características fundamentales de las comedias de capa y espada. Algunos de los trazos más evidentes son que los personajes tienen nombres comunes y viven en ciudades de la España contemporánea.

En la primera jornada de El hombre pobre todo es trazas Rodrigo parece aludir humorísticamente al crecimiento desmesurado de Madrid desde que en 1561 se instaló la corte en la ciudad. Aún en el año 1627 , en que se representó por vez primera esta comedia, la capital continuaba en pleno proceso de expansión urbana. Este fenómeno debía ser muy familiar para el espectador de los corrales de comedias madrileños, que reconocería inmediatamente el tono humorístico del criado Rodrigo, quejoso ante su amo por no haberle informado éste del nombre de la calle donde se encuentra la posada: 


\begin{abstract}
Lindo talle:
en Madrid, no es cosa llana, señor, que de hoy a mañana suele perderse una calle; porque según cada día se hacen nuevas, imagino, que desconoce un vecino hoy adonde ayer vivía.
\end{abstract}

(I, vv. 9-16)

La descripción de Madrid por parte de amo y criado no puede ser más elocuente. Rodrigo refiere a don Diego la seguridad que la ciudad supone para alguien que desea esconderse:

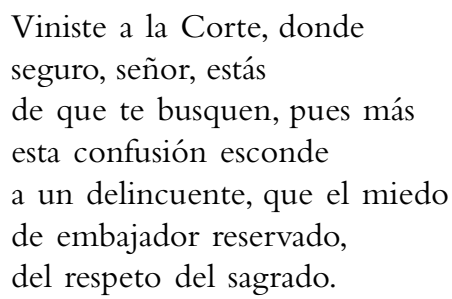

(I, vv. 70-77)

Esta referencia a una urbe populosa es reforzada y enriquecida por don Diego, que alude a la ciudad como una representación del mundo entero:

[...] la gran villa de Madrid:

esta nueva Babilonia,

donde verás confundir

en variedades, y lenguas

el ingenio más sutil.

Esta esfera soberana,

Trono, Dosel y Cenit

de un Sol español, que viva

eternos siglos feliz:

después que ciego admiré, después que admirado vi

todo el mundo en breve mapa $[\ldots]$.

(I, vv. 94-105) 
A pesar de la evidente intención elogiosa hacia la monarquía y su imperio que se desprende del discurso, la referencia inicial a «esta nueva Babilonia» adquiere un sentido admonitorio que parece aludir a la personalidad del mismo don Diego, su cuestionable moral y el doble papel que representará en la comedia ante las dos damas. Para reforzar el concepto que el personaje de don Diego tiene de Madrid, percibida como un escenario perfecto para sus correrías, obsérvese la comparación de la capital del reino con Babilonia («[...] donde verás confundir / en variedades, y lenguas / el ingenio más sutil»).

La dimensión fisica de Madrid, y su gran variedad de gentes es un motivo frecuente en las comedias de Calderón. La imagen de la ciudad como una gran urbe - teatro del mundo- es habitual en estas obras de ambiente madrileño. En El astrólogo fingido don Diego le pide a su amigo don Antonio que pregone la mentira de su condición de astrólogo por toda la ciudad, para así hacerla más creíble ante doña María y su padre. La petición es aceptada de buen grado y Morón se añade de buena gana al proyecto:

$$
\begin{aligned}
& \text { Sí, que en barrios divididos, } \\
& \text { como los demandaderos, } \\
& \text { seremos dos pregoneros; } \\
& \text { y yo iré dando alaridos, } \\
& \text { como un Médico [...]. } \\
& \text { (II, vv. 466-470) }
\end{aligned}
$$

Tras el acuerdo de dar «cuenta de medio Madrid» (II, v. 489], en el siguiente cuadro de la comedia, don Antonio se encuentra con don Carlos delante de la casa de doña Violante, y le explica la historia ficticia que han inventado, ante la credulidad de su oyente:

¡Qué cosas Madrid encierra! ique los mismos que tratamos aquí no nos conozcamos! ¡cuánto la inocencia yerra!

(II, vv. 582-585)

En la comedia También hay duelo en las damas, don Félix, despechado y celoso tras su última cita con doña Violante, ordena a Simón que ensille su caballo, pues desea abandonar Madrid inmediatamente (I, 
vv. 1039-1042). La respuesta del criado encierra una de las pocas referencias en esta comedia a la capital del reino, descrita de forma indirecta como una ciudad llena de atractivos para el viajero ocasional:

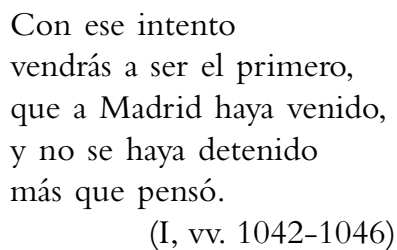

También en El maestro de danzar la ciudad de Madrid es presentada como una urbe populosa y acogedora. El criado Chacón lo comenta de esta manera a don Enrique:

En Madrid, patria de todos, pues en su mundo pequeño son hijos de igual cariño naturales, y extranjeros $[\ldots]$.

(I, vv. 12-15)

La configuración ideológica de la villa como capital del reino, extensa y populosa, tiene una relación íntima con la caracterización de las comedias de capa y espada, en un doble sentido: por una parte, como una de las marcas de cercanía de este subgénero y, por otra, como reflejo de los enrevesados argumentos que presentan las tramas dramáticas. Este difícil equilibrio entre la búsqueda continua de acciones asombrosas que sorprendan al espectador y la credibilidad de la comedia en el desarrollo de la acción dramática (necesaria para mantener el nexo de unión entre el espectador y el contexto de una trama que se sucede en un espacio dramático reconocible y contemporáneo a la representación teatral) representa un gran esfuerzo en la construcción de la comedia.

Esta tensión estructural entre el asombro del espectador del corral ante el desarrollo dramático de la obra y la credibilidad y verosimilitud de la trama está muy presente en la reflexión del dramaturgo, que en ocasiones desliza en algunos pasajes de sus comedias determinados comentarios - en boca de sus personajes - que ponen de manifiesto 
su conciencia de creación de un artefacto literario que posee unas características determinadas.

Por ejemplo, en la tercera jornada de Los empeños de un acaso, Hernando expone una extensa relación de sucesos (III, vv. 251-331), en la que presenta los hechos acaecidos desde que su amo don Juan le ordenó que se dirigiese a casa en el acto anterior (II, vv. 428-435). El dramaturgo pone en boca del criado el siguiente razonamiento:

$[\ldots]$ y al ver que nada el discurrir remedia, como amante celoso de comedia, que cuando varios soliloquios pasa, no reposa en la calle, ni en su casa.

(III, vv. 272-275)

Estas alusiones a la materia teatral aparecen con cierta frecuencia en las comedias de Calderón. En la última jornada de Los empeños de un acaso, en un momento determinado, doña Leonor solicita el perdón de don Alonso, y éste se lo concede a cambio de desposarse con don Félix. Parece acabar la obra, pero Hernando tercia, en una nueva referencia metaliteraria:
Pensarán que está acabada
la Comedia con casarse
los galanes, y las damas;
pues escuchen vuesarcedes, que otro pedacito falta.

(III, vv. 972-976)

El desenlace llega finalmente para presentar los versos finales de la obra, que zanjan la resolución de la pendencia entre don Félix, don Juan y don Diego — varias veces postergada a lo largo de la comedia - provocada por los infundados celos de don Félix y la herida que provocó al criado de don Juan. Como no podía ser de otra forma, es Hernando - humillado y descalabrado - el encargado de dar fin a la comedia, con el consabido perdón a la audiencia por las posibles faltas de la obra.

En la primera jornada de El hombre pobre todo es trazas, don Diego ironiza con Rodrigo acerca de la narración de hechos que está a pun- 
to de exponerle. Se trata de una clara referencia a las convenciones del lenguaje teatral:



En la misma comedia, y ya en la jornada final, varias mujeres se esconden en lo que aparenta ser un campo del paseo del Prado, detrás de San Jerónimo. La escena está llena de referencias metaliterarias hacia el espectador de la obra. Por ejemplo, la alusión de doña Beatriz a las «rotas tapias», tras las que se esconderán las damas no alude, con seguridad, a ningún elemento de atrezzo del corral de comedias, sino a una de las puertas laterales del escenario, tras las que deberían esconderse las actrices para simular estar en el lugar - aún sin ser visibles para el espectador - y asistir al posterior diálogo de los caballeros de los que se ocultan (III, vv. 759-769). Tras la salida de las dos damas, las dos criadas exponen irónicamente la poca habilidad del autor («estéril poeta es éste», III, v. 762) para representar o expresar dramáticamente la existencia de un campo en el tablado. Inés critica en la breve conversación con Isabel la escasez de plantas reales en el escenario («murta, jazmín o arrayán», III, v. 763) para esconder a las actrices sin necesidad de salir de escena por una de las puertas laterales. La habitual escasez de elementos escénicos en los corrales de comedias para sugerir espacios reales es aquí motivo de broma y el espectador coetáneo de la obra debía reconocer inmediatamente el guiño literario del dramaturgo.

Otro ejemplo de la plena conciencia de Calderón del artificio de su oficio y de las características del género de capa y espada es el inicio de la comedia El astrólogo fingido. Esta obra se inicia con la narración de los dos años de cortejo de don Juan —un noble caballero con escasos recursos económicos- a doña María. La larga resistencia inicial de la dama ante el cortejo de don Juan se desplomará tras dos años de asedio, después del anuncio del caballero de su inminente par- 
tida a Flandes. A pesar de las convenciones del género de capa y espada, el amor de la dama por un hombre de tan escasa hacienda debía parecer tan endeble al público del corral de comedias, que Calderón se ve obligado a la ironía, poniendo en boca de Beatriz un comentario de carácter metaliterario que parece aludir a la artificiosidad de la trama:
Querer al de menos fama, hacienda y nobleza, dama de Comedias me pareces, que toda mi vida vi en ellas aborrecido el rico, y favorecido el pobre, donde advertí su notable impropiedad. Pues las Comedias son una viva imitación que retrata la verdad de lo mismo que sucede a un pobre, verle estimar, ¿cómo se puede imitar, si ya suceder no puede?

$$
\text { (I, vv. 97-111) }
$$

Al final de la primera jornada de esta misma comedia, una nueva referencia metaliteraria - en boca del criado Morón a los espectadores del corral - parece aludir al desarrollo futuro de la acción dramática, apelando al interés y a la curiosidad del público: «[...] ha de nacer deste amor, / señor, un notable cuento» (I, vv. 901-902).

En fin, hay muchas más muestras de este tipo en Calderón, que demuestran que el dramaturgo es muy consciente del juego escénico y de los recursos técnicos que utiliza para adaptarse a las características de este tipo de comedias. En También hay duelo en las damas, don Félix se queda solo en escena en un momento de la segunda jornada. El artificio de la comedia - un elemento sustantivo del género, que busca sobre todo la sorpresa del espectador- ya es evidente a estas alturas de la obra, y quizás por ello el dramaturgo pone en boca del caballero un comentario que sugiere sutilmente al enredo argumental de este tipo de comedias: 


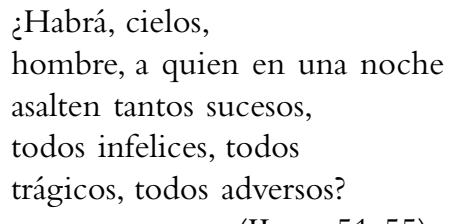

(II, vv. 51-55)

Todos los ejemplos expuestos muestran unas características comunes de Los empeños de un acaso en el tratamiento de ciertos aspectos que aparecen en otras comedias de capa y espada de Calderón de la Barca. Aunque es cierto que existe un sustrato común de convenciones estilísticas y temas compartido por todos los dramaturgos de la comedia del Siglo de Oro, puede observarse que Calderón desarrolla de forma específica determinados procedimientos en muchas de sus obras de capa y espada.

Los indicios apuntados en este artículo son sólo algunos ejemplos que deberían ser ampliados con otros estudios complementarios de mayor alcance, como pruebas léxicas y estilísticas en un número significativo de comedias que confirmasen la atribución de Los empeños de un acaso a Calderón. A pesar de todas las prevenciones que requiere un análisis de este tipo, pueden constatarse numerosas coincidencias en el tratamiento de los tres aspectos que hemos comentado: la mención del locus amoenus, la consideración de la ciudad de Madrid y los comentarios metaliterarios que el dramaturgo hace aparecer en sus comedias. 


\section{Bibliografía}

Arellano, I., "Convenciones y rasgos genéricos en la comedia de capa y espada», Cuadernos de Teatro Clásico, 1, 1988, pp. 27-49.

Calderón de la Barca, P., Segunda parte de comedias, Madrid, María de Quiñones, 1637.

- Tercera parte de comedias, Madrid, Domingo García Morrás, 1664.

- Sexta parte de comedias, Madrid, Juan Sanz, 1715.

- Comedias, ed. J. E. Hartzenbusch, Madrid, Ribadeneyra, 1850, vol. 4.

- Cuarta parte de comedias, ed. S. Neumeister, Madrid, Biblioteca Castro, 2010a.

- Verdadera quinta parte de comedias, ed. J. M. ${ }^{a}$ Ruano de la Haza, Madrid, Biblioteca Castro, 2010b.

Cayuela, A., Alonso Pérez de Montalbán un librero en el Madrid de los Austrias, Madrid, Calambur, 2005.

Coenen, E., «En los entresijos de una lista de comedias de Calderón», Revista de Filología Española, 89, 2009, pp. 29-56.

Mesonero Romanos, R., Dramáticos contemporáneos de Lope de Vega, Madrid, Ribadeneyra, 1858, vol. 2.

Pérez de Montalbán, J., Para Todos, Huesca, Pedro Blusón, 1633.

- Primero tomo de las comedias del doctor Juan Pérez de Montalbán, Madrid, Imprenta del Reino, 1635.

- Segundo tomo de las comedias del doctor Juan Pérez de Montalbán, Madrid, Imprenta del Reino, 1638.

Profeti, M. ${ }^{a}$ G., Per una bibliografia di J. Pérez de Montalbán, Verona, Universitá degli Studi di Padova, 1976 (addenda et corrigenda, 1982).

- "Los empeños de un acaso de Pedro Calderón, Los empeños que se ofrecen de Juan Pérez de Montalbán», Segismundo, 6, núm. 1, 1983, pp. 249-254. 